\title{
Two-case report of surgical treatment of rhinophyma with coblation
}

Georgi Iliev, Polina Ivanova

ENT Department, University Hospital Saint Marina, Medical University of Varna, Bulgaria
Rhinology Online, Volume 1: 30 - 34, 2018

http://doi.org/10.4193/RHINOL/18.007

*Received for publication:

January 31, 2018

Accepted: March 12, 2018

Published: April 1, 2018

\begin{abstract}
Introduction: Rhinophyma is a tumor-like enlargement of the skin of the nose, affecting dorsum nasi and the apex. While the aetiology is unknown, dermatosis rosacea can be indicated as one of the main causes. Rhinophyma is characterized by reddish, swollen bumpy surface of the nose, overgrowing of scar-like tissue and augmentation of the sebaceous glands. Epidemiologically, rhinophyma affects mainly men between the ages of 50 and 70.
\end{abstract}

Purpose of the study: To present an overview of the disease, based on our personal experience with the condition and the associated surgical treatment.

Materials and methods: Our findings are based on the cases of two patients over a period of two years, diagnosed with the condition rhinophyma, who underwent surgical treatment in "Saint Marina" hospital. The excision was made using the "Coblator II system".

Results: Due to unresponsiveness to conventional treatment, surgical removal of the rhinophyma was necessary.

Conclusion: Rhinophyma is a rare condition, causing discomfort to the patient and deforming the nose. Surgical intervention shows most effective results in the treatment of this disease.

Key words: case report, coblation, rhinophyma, rosacea, surgical treatment

\section{Introduction}

Rhinophyma is a benign lesion of the skin of the nose that does not affect the airway. It is characterized by bulbous hypertrophy of the soft tissue of the nose including the sebaceous glands found there with exophytic growth. The progressive disfiguring condition substantially affects patients' quality of life.

The condition has supposedly been known since medieval times as it was first illustrated in the portrait called "An Old Man and his Grandson" by Domenico Ghirlandaio in 1490. The picture depicted a noticibly deformed bulbous nose which strongly resembles what is today known as a rhinophyma ${ }^{(1)}$.

The medical term itself was coined by the Austrian dermatolo- gist Ferdinand von Hebra back in 1845 - he described the condition as third degree acne rosacea. (rhis: Greek for nose; phyma: Greek for growth) ${ }^{(1,2)}$.

Conservative treatment has little effect on established rhinophyma. Remedy can be obtained on rosacea, where the treatment options are numerous such as topical corticosteroids (metronidazole) or topical azelaic acid, also oral antibiotics can be prescribed due to their anti-inflammatory and antimicrobial action. Whereas rhinophyma responds poorly to medical treatment and surgery is usually required ${ }^{(3)}$. The most efficient treatment for rhinophyma is surgical intervention, while the techniques of excision vary. 


\section{Materials and methods}

Ethical approval

This is not a research study, no ethical approval is required.

\section{Consent}

Written informed consent was obtained from the patients for publication of this case report and accompanying images.

\section{Case reports}

Our findings are based on a retrospective study which follows the cases of 2 patients over a period of two years (2017-2018) diagnosed with the condition. All of subjects underwent surgical treatment in Saint Marina Hospital in Varna. The patients' medical history relating to the condition will be presented in full detail. The goal of this study is to report on the findings, provide commentary on the hands-on experience and propose an alternative in the treatment of rhinophyma. The research work has been reported in line with the process criteria. The UIN (unique identifying number) of this case report is 3250 .

We report our experience with the following two patients. Patient One is a 74-year-old male with history of rhinophyma spanning 3 years with no sign for preceding rosacea, nor alcohol abuse or excessive intake. The patient reported the condition as a small papule in the beginning. The bulbous growth on his lower nose, engaging the tip of the nose, was disturbing his appearance and recently started causing difficulty breathing (Figure 1).

Patient Two is a 78-year-old male presented with a 10-year history of a growing mass on the nose. Physical examination revealed large, bulbous and erythematous-appearing nose, constituting a severe case of rhinophyma. The nasal lesion, due to its size and mass, caused nasal deformity, nasal obstruction of the external nasal orifices, difficulty in eating due to ptosis through lips and also troubling the sight of the patient. The medical history revealed neither heavy alcoholism (less than $20 \mathrm{~g}$ alcohol per day), nor any previous dermatological disease (Figure 2).

\section{Surgery}

Both patients underwent surgery under general anaesthesia with the surgical technique - "Coblator II system", the main advantage of which is that it cuts and stops bleeding simultaneously, reducing blood loss to a minimum. The surgical treatment consisted in total excision of the abnormal nasal formation, with preservation of the cartilages, perichondrium and periosteum. The surgical specimen was sent for histopathological examination. Both patients responded well to the procedure,
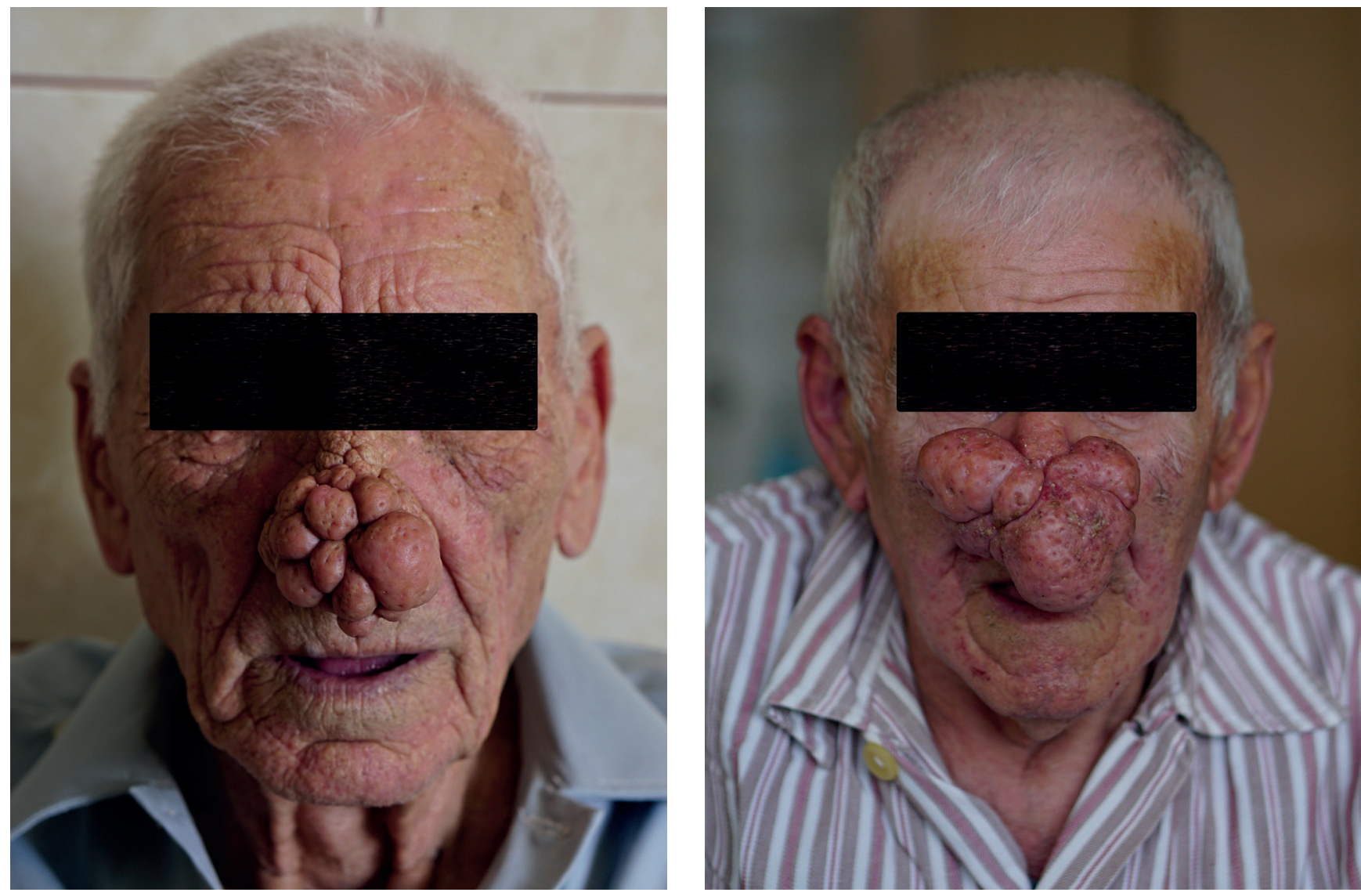

Figure 1. Patient №1 Preoperative view.

Figure 2. Patient №2 Preoperative view. 
no postoperative complications were observed, neither wound infection. The patients were prescribed "Cicatridina spray 125 $\mathrm{ml}$ " which main components are Hyaluronic acid/Vitamin $\mathrm{E}$ for local aplication on the surgical wound for better and faster healing and also "Oxycort spray $30 \mathrm{ml}$ " which is composed of Oxytetracycline hydrochloride and Hydrocortisone in order to prevent infections.

\section{Results}

All patients were successfully treated with satisfying functional and aesthetic results. The diseased tissues examined by the anatomopathologist display the histological presentation of rhinophyma. Presence of neoplastic cells was not observed. The nasal dorsum was re-epithelialized within 25 days. The surgical wound healed successfully with secondary intention and a restored normal nasal architecture. In both cases, their condition was followed-up and the patients reported improved breathing and contentment with their appearance. No recurrence was observed during the follow-up period (Figures 3 and 4).

\section{Discussion}

Rhinophyma is a rare condition affecting almost exclusively males as its incidence is with a male-female ratio of $12: 1$. It usu- ally occurs between ages 50-70 (4). The etiology of the disease is currently unknown. In the past, rhinophyma was considered a clinical sign of heavy alcohol consumption in males but this relationship has never been proven as the condition occurs as frequently as in people who do not drink alcoholic beverages. Another suspicious etiological factor is the presence of acne rosacea as some authors classify rhinophyma as a late-stage manifestation of rosacea ${ }^{(5-7)}$. Fortunately, only a small minority of patients suffering from rosacea progress to develop rhinophyma later on. Other possible factors correlating with rhinophyma are high levels of steroid hormones, the microorganism Demodex Follicolorum and vitamin deficiency ${ }^{\left({ }^{8}\right)}$. Currently, these are only speculations, the real cause is still unclear. It is safe to state that this disease is multifactorial in its origin.

The surgical treatment includes total excision or subtotal eradication of the affected nasal tissue. Different surgical techniques may be applied but there is still no established gold standard among them. Some of the treatment options include: conventional dermabrassion, carbon dioxide laser, mono- or bipolar electroknife, cryosurgery and coblation surgery. Dermabrasion involves using a tool as a wire brush which by rotating rapidly removes the superficial layers of the affected skin. Its disadvantage is bleeding and the risk of cutting too deep, which

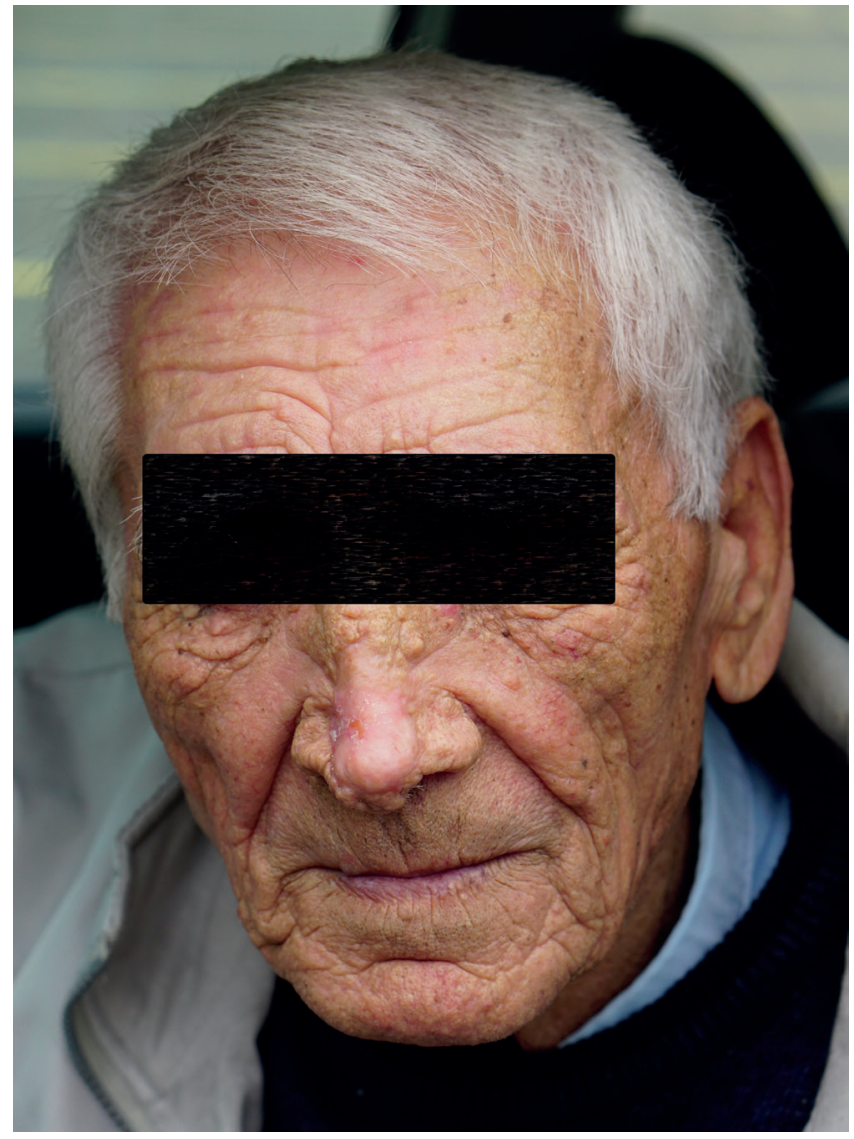

Figure 3. Patient №1 Postoperative view after one month.

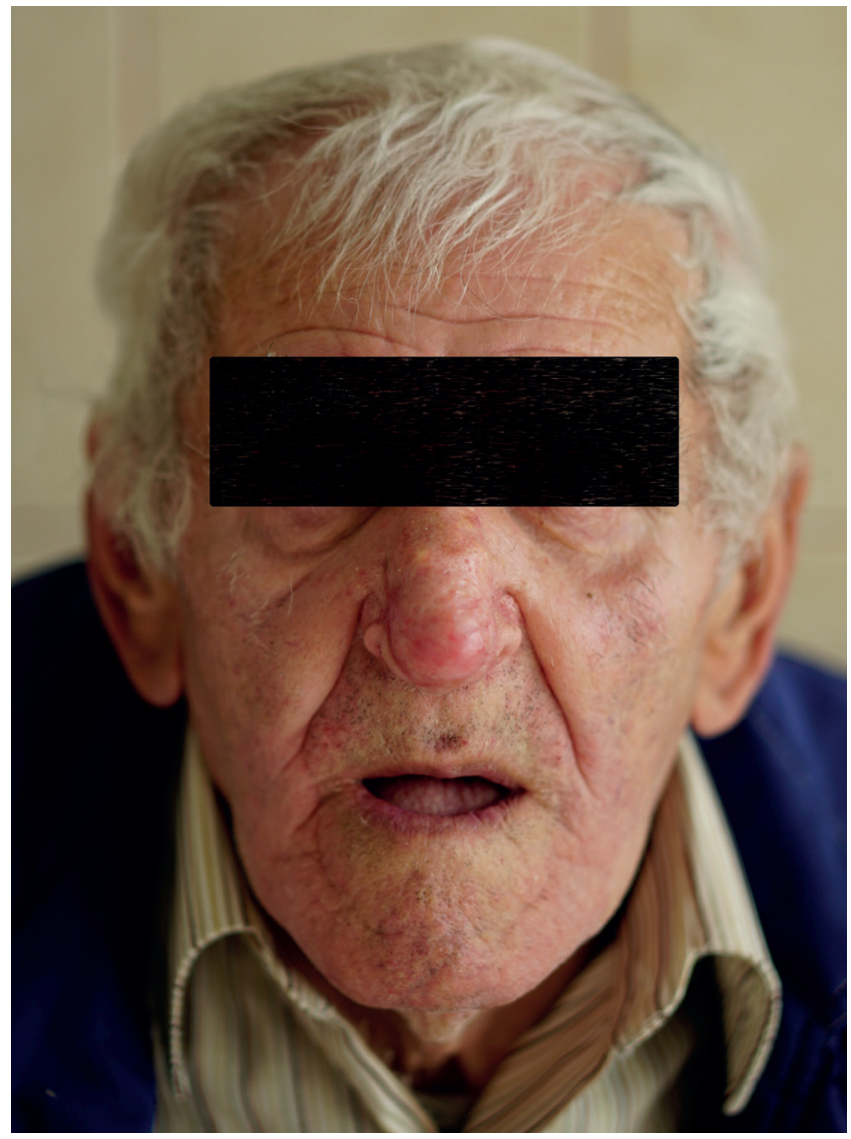

Figure 4. Patient №2 Postoperative view after one month. 

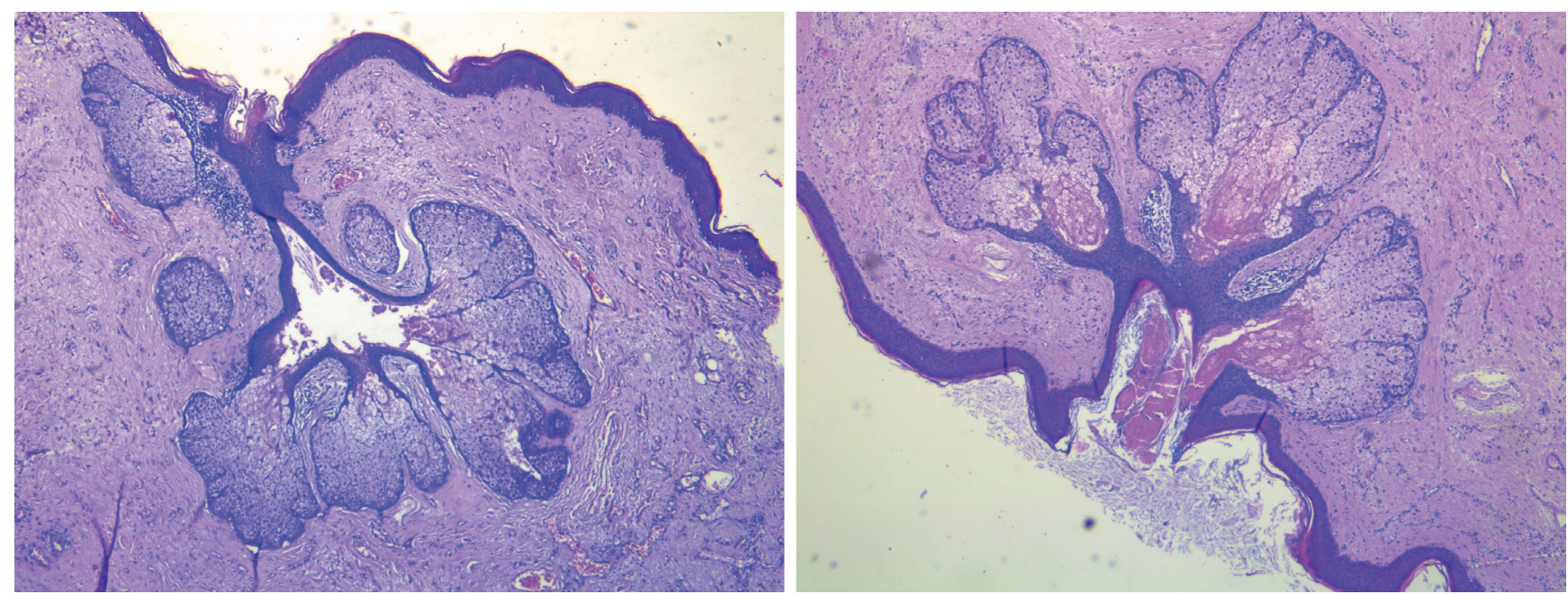

Figure 5. Histopathological examination, HE, x10.

can lead to scarring. $\mathrm{CO}_{2}$ laser is the most common method of treating thickened skin. It removes the imperfections of the skin's surface. Carbon dioxide laser wavelights penetrate the top skin layers creating thermal damage to the skin leading to new collagen production. This technique causes less amount of bleeding, however, there is a risk of pigmentary changes and scarring ${ }^{(9)}$. Electrosurgery uses devices that deliver high frequency electrical currents that heat up and doing so remove excess tissue. It may cause bleeding. Cryosurgery uses extreme cold temperatures to remove unwanted tissues by freezing. The main disadvantage of the cryosurgery is the less control over the depth of the surgery. Cold excision decortication methods may cause significant intraoperative bleeding, which can obscure the operative field and jeopardize the precision of the procedure ${ }^{(10)}$. Our surgical approach is based on the technique coblation. Coblation offers a practical alternative to the mentioned methods with better results. With coblation there is a minimal thermal penetration and, therefore, minimal damage to the surrounding tissue which reduces the scarring. Skin grafts or local flaps can be used to cover the defected are, or the wound can be allowed to re-epithelialize spontaneously.

With the "Coblator II system" which was used in the surgeries of the reported patients focused low heat dissection is applied. As the energized plasma demolishes the diseased tissue at low temperature, hemostasis and minimal damage to the healthy neighboring tissue is observed ${ }^{(11)}$. The coblation technique, unlike previous radiofrequency methods, uses bipolar current to create a plasma field, which can then split tissue. Creation of the field occurs at temperatures of only $60^{\circ} \mathrm{C}$ to $70^{\circ} \mathrm{C}$, which is less than those produced with conventional radiofrequency and electrocautery ${ }^{(12)}$. Coblation offers several advantages over carbon dioxide laser decortication, including almost no bleeding, no wiping, no smoke, no requirement for laser precautions, and a much lower capital equipment cost ${ }^{(13)}$.

The morphologic characteristics of rhinophyma are thick nasal cutaneous layer, nodularity covered by atrophic skin with expanded pores. The tumor is painless and while pressing it can appear an increased quantity of whitish sebum with fetid smell. The need for histologic examination of all surgically removed tissue in patients with rhinophyma is highlighted. Several macroscopic changes, including ulceration, drainage and a rapid growth pattern, should alarm the physician and be considered as suspicious of a malignant degeneration. Unexpected clinical modifications of a preexisting long-lasting silent rhinophyma could indicate the possibility of hidden malignancy rather than a full sense rhinophyma condition ${ }^{(14)}$. Histophatologically, a massive hyperplasia of sebaceous glands filed with keratin and sebum can be observed with marked dermal fibrosis and telangiectasia accompanied by perivascular and perifollicular inflammatory infiltrate with lymphocytes and histiocytes (Figure 5).

\section{Conclusion}

Rhinophyma is a condition causing physiological as well as psychological problems for the patients, who seek fast and effective solution to this deforming disease. Many surgical techniques have been advocated and all of them have their advantages and disadvantages. Nevertheless, we recommend management of rhinophyma with the surgical approach coblation which was employed in this research as one of the most functional-based on the controlled excision, haemostasis in low temperatures, minimal blood loss and minimized risk of complications. Finally, regardless of rhinophyma being a benign lesion, the risk of malignancies hidden within it is a major issue.

\section{Acknowledgements}

The authors declare no sources of funding. 


\section{Authorship contribution}

G.I. conceived of the presented idea and carried out the clinical work on the patients. P.I. wrote the manuscript in consultation with G.I. All authors discussed the results and contributed to the final manuscript.

\section{Conflict of interest}

None declared. The authors have no financial, consultative, institutional, and other relationships that might lead to bias or conflict of interest.

\section{References}

1. Clarós P, Sarr MC, Nyada FB, Clarós A. Rhinophyma: Our experience based on a series of 12 cases. Eur Ann Otorhinolaryngol Head Neck Dis. 2017 Sep 21. pii: S18797296(17)30128-X

2. Oswal V, Remacle M. Principles and Practice of Lasers in Otorhinolaryngology and Head and Neck Surgery. 2nd edition, Amsterdam, Kugler Publications, c2014, Chapter 27, p467.

3. Aldrich N, Gerstenblith M, Fu P, et al. Genetic vs Environmental Factors That Correlate With Rosacea: A Cohort-Based Survey of Twins. JAMA Dermatol. 2015;151(11):12131219.

4. Bogetti P, Boltri M, Spagnoli G, Dolcet M Surgical Treatment of Rhinophyma: A Comparison of Techniques. Aesth. Plast. Surg. 2002 Jan-Feb; 26(1):57-60.

5. Selig HF, Lumenta DB, Kamolz LP. The surgical treatment of rhinophyma-Complete excision and single-step reconstruc tion by use of a collagen-elastin matrix and an autologous non-meshed splitthickness skin graft. Int J Surg Case Rep.
2013:4(2):200-3.

6. Powell F.C. Clinical practice. Rosacea. N Engl J Med. 2005 Feb;352(8):793-803.

7. Sadick H, Goepel B, Bersch C, Goessler U, Hoermann K, Riedel F. Rhinophyma: diagnosis and treatment options for a disfiguring tumor of the nose. Ann Plast Surg. 2008 Jul;61(1):114-20.

8. Curnier A, Choudhary S. Triple approach to rhinophyma. Ann Plast Surg. 2002 Aug;49(2):211-4.

9. Weinstein C. Carbon dioxide Laser resurfacing: Long-term follow-up in 2123 patients. Clin Plast Surg. 1998; 25:109-30.

10. Goon PKY, Dalal M, Peart FC. The gold standard for decortication of rhinophyma: combined erbium-YAG/CO2 laser. Aesthetic Plast Surg 2004; 28: 456-460.

11. Sahin C, Turker M, Celasun B. Giant rhinophyma: Excision with coblation assisted surgery. Indian J Plast Surg. 2014 Sep-Dec; 47(3): 450-452.

12. Myers E. Operative Otolaryngology: Head and Neck Surgery 2nd Edition 6th August 2008 p169-183

13. Hugh E. Coblation-assisted decortica- tion for the treatment of rhinophyma, The Laryngoscope, June 2009, 119:6, p10821084

14. Lazzeri D, Colizzi L, Licata G, Pagnini D, Proietti A, Alì G. Malignancies within rhinophyma: report of three new cases and review of the literature. Aesthetic Plast Surg. 2012 Apr;36(2):396-405.

Polina Petrova Ivanova

ENT Department

University Hospital Saint Marina Medical University of Varna, bul. "Hristo Smirnenski" 1 9010 Varna

Bulgaria

Tel: +35-989-686 3941

E-mail:ppivanovax@gmail.com 